NOTICE: This is the peer reviewed version of the following article: Elena Pazos, Manuel García-Algar, Cristina Penas, Moritz Nazarenus, Arnau Torruella, Nicolas Pazos-Perez, Luca Guerrini, M. Eugenio Vázquez, Eduardo Garcia-Rio*, José L. Macareñas* and Ramon A. Alvarez-Puebla* (2016), SERS Surface Selection Rules for the Proteomic Liquid Biopsy in Real Samples: Efficient Detection of the Oncoprotein cMYC. J. Am. Chem. Soc., 138, 14206-14209 [DOI: 10.1021/jacs.6b08957]. This article may be used for non-commercial purposes in accordance with ACS Publications Terms and Conditions for self-archiving.

\title{
SERS Surface Selection Rules for the Proteomic Liquid Biopsy in Real Samples: Efficient Detection of the Oncoprotein c-MYC
}

Elena Pazos, ${ }^{1}$ Manuel Garcia-Algar, ${ }^{1,2}$ Cristina Penas, ${ }^{3}$ Moritz Nazarenus, ${ }^{2}$ Arnau Torruella, ${ }^{1,2}$ Nicolas Pazos-Perez, ${ }^{2}$ Luca Guerrini, ${ }^{2}$ M. Eugenio Vázquez, ${ }^{3}$ Eduardo Garcia-Rico, ${ }^{4 *}$ José L. Mascareñas $^{3 *}$ and Ramon A. Alvarez-Puebla ${ }^{1,5 *}$

\footnotetext{
${ }^{1}$ Universitat Rovira i Virgili and Centro de Tecnología Química de Catalunya, Carrer de Marcellí Domingo s/n, 43007 Tarragona, Spain.

${ }^{2}$ Medcom Advance S.A., Av. Roma, o884o Barcelona, Spain.

${ }^{3}$ Centro Singular de Investigación en Química Biolóxica e Materiais Moleculares (CIQUS) and Departamento de Química Orgánica, Universidade de Santiago de Compostela, 15782 Santiago de Compostela, Spain.

${ }^{4}$ Department of Clinical Oncology, Hospital Universitario Hm Madrid-Torrelodones, 28250 Madrid, Spain

${ }^{5}$ ICREA, Passeig Lluís Companys 23, o801o Barcelona, Spain.
}

\section{Supporting Information Placeholder}

\begin{abstract}
Blood-based biomarkers (liquid biopsy) offer extremely valuable tools for the non-invasive diagnosis and monitoring of tumors. The protein c-MYC, a transcription factor that has been shown to be deregulated in up to $70 \%$ of human cancers, can be used as a robust proteomic signature for cancer. Herein, we developed a rapid, highly specific and sensitive SERS assay for the quantification of c-MYC in real blood samples. The sensing scheme relies on the use of specifically designed hybrid plasmonic materials and their bioderivatization with a selective peptidic receptor modified with a SERS transducer. Peptide/c-MYC recognition events translate into measurable alterations of the SERS spectra associated with a molecular orientation of the transducer, in agreement with the surface selection rules. The efficiency of the sensor is demonstrated in cellular lines, healthy donors and a cancer patient.
\end{abstract}

The molecular characterization of tumors is consistently applied in clinical oncology to guide treatment decisions. These analyses are performed on solid tissues acquired through an invasive biopsy at diagnosis. However, tissue biopsies are challenging as they are costly, painful, or potentially risky for the patient. Thus, the development of noninvasive methods to detect and monitor tumors is a major need in oncology. Blood-based biomarkers (liquid biopsy) ${ }^{1}$ have a considerable potential for the diagnosis and monitoring of cancer. Circulating tumor cells $(\text { CTC })^{2}$ and circulating tumor nucleic acids ${ }^{3}$ are all options, alongside existing and new protein markers. ${ }^{1}$. However, the protein expression patterns in plasma circulating tumor cells as well as in peripheral blood mononuclear cells fractions remain a largely unexplored aspect. ${ }^{1}$

The protein c-MYC is a helix-loop-helix leucine zipper (bHLHZ) transcription factor encoded by the corresponding c-myc gene that plays a major role in coordinating cellular metabolism with cell cycle and it has been shown to be elevated or deregulated in up to $70 \%$ of human cancers. ${ }^{4}$ Unlike other proto-oncogenes whose activity is dependent on mutations, truncations or gene fusions, the oncogenicity of c-myc gene is usually secondary to loss of transcriptional control leading to over-expression and accumulation of normal protein. ${ }^{5}$ Furthermore, the c-MYC protein is not associated with any specific transcriptional program, but it appears to be a universal amplifier of gene expression, increasing the transcription at all active promoters. ${ }^{6}$ Thus, the evaluation of the concentration of this protein in blood can be used as a criteria for the diagnosis and monitoring of tumors.

Identification and quantification of proteins in blood is normally performed by using standard immunological techniques such as Western Blot (WB) or ELISA. Although robust, these methods are tedious, lengthy, expensive and, in the case of $\mathrm{WB}$, have low sensitivity. In recent years, surfaceenhanced Raman scattering (SERS) spectroscopy ${ }^{7}$ has emerged as an excellent alternative for the detection, quantification and characterization of biopolymers. SERS has been employed directly for ultrasensitive quantification of prionic, ${ }^{8}$ green ${ }^{9}$ or yellow ${ }^{10}$ fluorescent proteins, and others. ${ }^{11}$ Most of these determinations were carried out in lab solutions as 

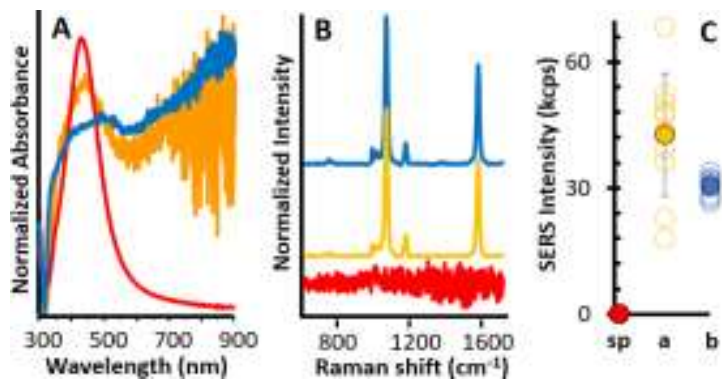

Figure 1. (A) UV-Vis spectra of the AgNPs in solution (red) and aggregated either in cast film (yellow) or on the silica beads (blue). (B) SERS spectra and (C) comparison of the intensities $\left(1075 \mathrm{~cm}^{-1}\right)$ of MB-H1 on a spin-coated film of non-aggregated AgNPs (sp, red), a film of aggregated AgNPs produced by drop casting and air-drying $50 \mu \mathrm{L}$ of solution in a glass slide (a, yellow), and $\mathrm{SiO}_{2} @ \mathrm{Ag}$ (b, blue).

the analysis of protein markers in real samples is extremely challenging. This is due to both the intrinsic complexity of real samples, comprising a myriad of components, and the usually low concentration $(\sim \mathrm{pg} / \mathrm{mL})$ and poor SERS crosssection $^{12}$ of the targets. A possible solution relies on the functionalization of the plasmonic materials with chemical species (chemoreceptors) with high SERS cross-section and displaying high binding affinity and specificity for the target protein. ${ }^{12}$ In this approach, detection is determined by the spectroscopic changes in the chemoreceptor SERS spectrum upon binding with the target. ${ }^{13}$ Species such as antibodies, aptamers or peptides can be used as chemoreceptors. ${ }^{14}$ However, these molecules are often characterized by a remarkable small SERS activity, which severely limits their application for direct ultradetection. This issue can be addressed by derivatizing the macromolecular receptor with a terminal moiety with high SERS cross-section and affinity for the plasmonic surface to mediate the interaction between the receptor and the metallic substrate). ${ }^{1{ }^{a}}$ In this communication, we designed and prepared a SERS-active peptideconjugate (MB-Hı) that binds c-MYC with high affinity and selectivity. Silica microbeads rather homogeneously coated with silver nanoparticles $\left(\mathrm{SiO}_{2} @ \mathrm{Ag}\right)$ were appropriately biofunctionalized with the chemoreceptor $\left(\mathrm{SiO}_{2} @ \mathrm{Ag} @ \mathrm{MB}-\mathrm{H1}\right)$ and successfully used for the quantification of c-MYC protein on laboratory and real samples from cancer patients and healthy donors.

The organic chemoreceptor is based on a double mutant peptide $\left(\mathrm{Ser}^{520} \rightarrow\right.$ Ala, $\mathrm{Phe}^{522} \rightarrow$ Ala) derived from the helix 1 $(\mathrm{H1})$ of the helix-loop-helix region of c-MYC $\left({ }^{515} \mathrm{NELKRAFAALRDQI}{ }^{528}\right.$, H1-S6A,F8A), which is known to interact with high affinity and selectivity with c-MYC. ${ }^{15}$ In order to build the SERS probe, we orthogonally attached a 4mercaptobenzoyl unit to the sidechain amino group of a Lys residue appended at the $\mathrm{C}$-terminus of the $\mathrm{H}_{1}-\mathrm{S} 6 \mathrm{~A}$,F8A peptide. Such modification should not alter the intrinsic helical propensity of the peptide, or its c-MYC-binding properties. The synthesis of the MB-H1 peptide-conjugate is described in the supporting information (S.I). Citrate-capped silver nanoparticles (AgNPs) of ca. $65 \mathrm{~nm}$ diameter (Figures $\mathrm{S}_{5} \mathrm{~A}$ and B) were electrostatically deposited onto $8 \mu \mathrm{m}$ diameter silica beads $\left(\mathrm{SiO}_{2} @ \mathrm{Ag}\right)$. Previously, the negatively charged silica microparticles were sequentially coated with polyelectrolytes (polyethyleneimine, PEI, positive), polyacrylic acid (PAA, negative), and again PEI, using the layer-by-layer (LbL) assembly protocol (Figures $\left.\mathrm{S}_{5} \mathrm{C}-\mathrm{E}\right) .^{16} \mathrm{UV}$-Vis spectrum of the prepared AgNPs (Figure $1 \mathrm{~A}$ ) shows a defined localized sur-
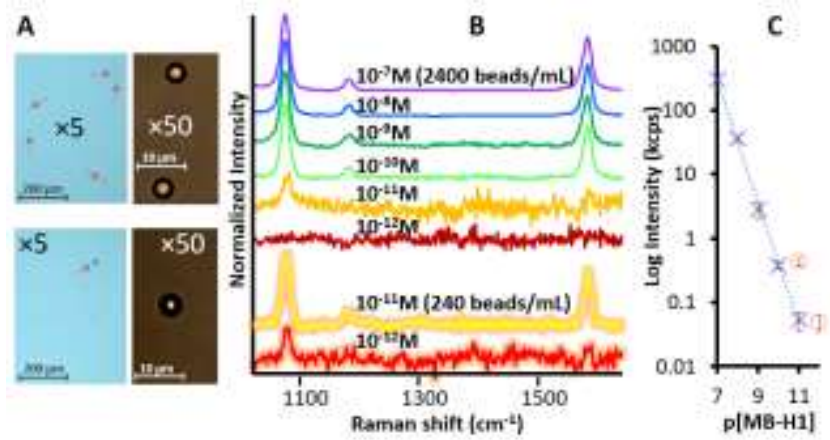

Figure 2. (A) Optical images at low $\left(\times_{5}\right)$ and high $(\times 50)$ magnification of beads from a $100 \mu \mathrm{L}$ aliquot of suspensions with concentrations of 2400 (upper panels) and 240 (bottom panels) beads $/ \mathrm{mL}$. (B) SERS spectra of $\mathrm{MB}-\mathrm{H}_{1}$ at different concentration on $\mathrm{SiO}_{2} @ \mathrm{Ag}$ ( 2400 beads $/ \mathrm{mL}$ and, highlighted, 240 beads $/ \mathrm{mL}$ ), and (C) their corresponding intensity at $1075 \mathrm{~cm}^{-1}$.

face plasmon resonance centered at $449 \mathrm{~nm}$. Nanoparticle deposition onto a solid support results in the appearance of an intense and broad feature at longer wavelength, which is an indicator of the interparticle coupling. The SERS fingerprint of $\mathrm{MB}-\mathrm{H}_{1}$ on $\mathrm{SiO}_{2} @ \mathrm{Ag}$ is shown in Figure $1 \mathrm{~B}$ (blue curve). Remarkably, the $\mathrm{SiO}_{2} @ \mathrm{Ag}$ offer large surface area, close adsorbent-adsorbate interaction and high density of electromagnetic hot spots, thus combining the benefits of colloids and films, while overcoming important limitations of both. In this regard, we also produced silver-coated glass slides via spin-coating of either non-aggregated (Figure S6B) or aggregated MB-H1-modified AgNPs to compare and evaluate the SERS efficiency of $\mathrm{SiO}_{2} @ \mathrm{Ag} @ \mathrm{MB}-\mathrm{H}_{1}$. Results (Figures $1 \mathrm{~B}$ and $\mathrm{C}$ ) indicate that no appreciable SERS signal is observed for the non-aggregated AgNPs slides, while the aggregated AgNPs layer and $\mathrm{SiO}_{2} @ \mathrm{Ag}$ display similar SERS intensities but with smaller standard deviation for the case of beads. The large size of these beads allows their easy localization with a low magnification objective (e.g., $\times 5$ ) for the later scanning with a higher resolution objective (e.g., $\times 50$ or $\times 100$ ) (Figure $2 \mathrm{~A}$ ). This paves the way for a drastic reduction of the amount of plasmonic material required for sensing, which in turn improves the sensitivity by increasing the number of molecules per bead ratio. This is exemplified in Figures $2 \mathrm{~B}$ and $\mathrm{C}$ which show that SERS of $\mathrm{MB}-\mathrm{H}_{1}$ is distinguishable down to $10 \mathrm{pM}$ for a particle concentration of 2400 beads $/ \mathrm{mL}$, while lower $\mathrm{SiO}_{2} @ \mathrm{Ag}$ amounts (240 beads $/ \mathrm{mL}$ ) allows for detection down to $1 \mathrm{pM}$.

Capturing of the c-MYC target by $\mathrm{MB}-\mathrm{H}_{1}$ bound to $\mathrm{SiO}_{2} @ \mathrm{Ag}$ beads could result in a large set of different perturbations on the SERS spectra of the mercaptobenzoyl moiety, ranging from subtle shifts of the vibrational features to the appearance of new bands. For interpreting such variations, we acquired the Raman and SERS spectra of the SERS-active terminal moiety (4-mercapto- $N$-methylbenzamide, MMB), and those of MB-Hi before and after reaction with c-MYC (Figure $3 \mathrm{~A}$ ). The SERS spectra of MMB and MB-Hi display similar vibrational patterns but with some differences in relative intensities. This result points toward a slight change of the molecular orientation of the mercaptobenzene group on the silver surface when is coupled with a larger molecule such as $\mathrm{H}_{1}$, in full agreement with the surface selection rules. ${ }^{17}$ Such perturbation is exacerbated upon binding with the very large c-MYC protein. 

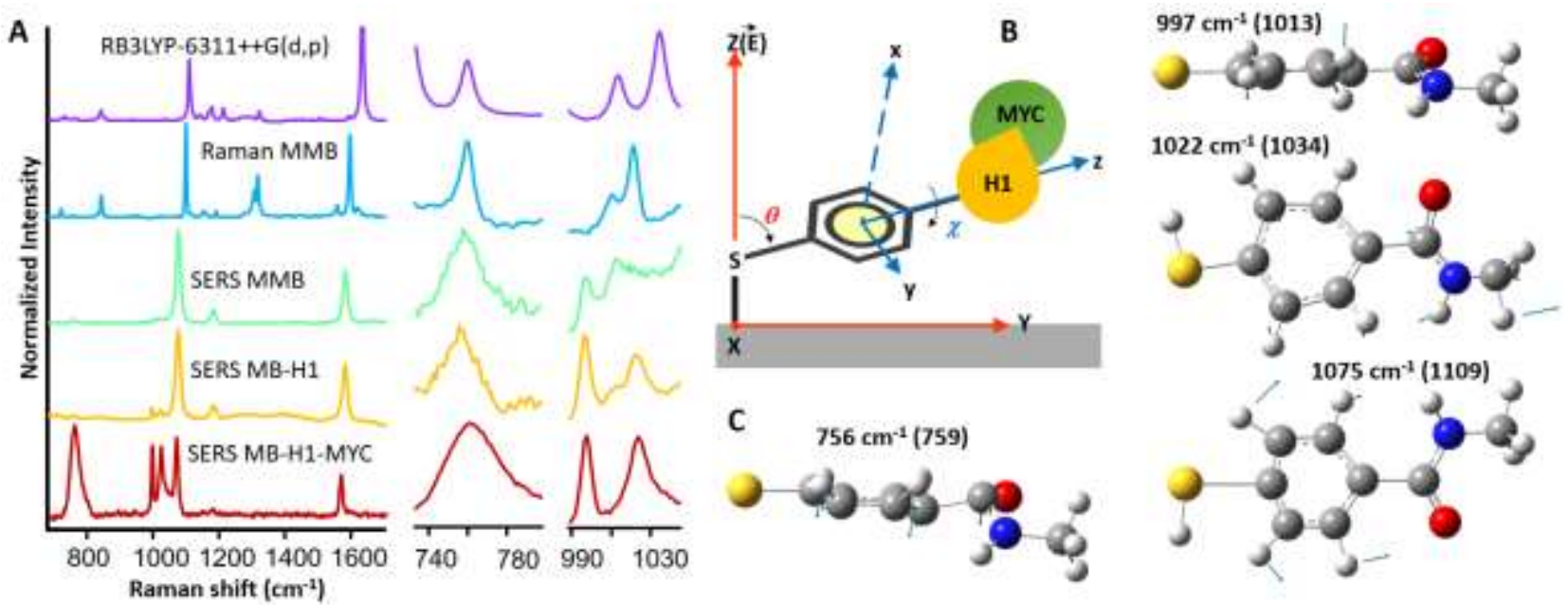

Figure 3. (A) Theoretical and experimental Raman spectrum of MMB and SERS spectra of MMB, MB-H1, and MB-H1 in presence of c-MYC, on $\mathrm{SiO}_{2} @$ Ag. Magnification of the spectral windows between 730-80o and 990-1050 are also shown. (B) Model used in the estimation of the molecular orientation. Absolute orientation of the molecule on the surface and relative orientation of the ring over the surface are represented by XYZ and xyz axes, respectively. (C) Vibrational mode assignation as described by the DFT calculations (theoretical value into brackets).

In order to identify the vibrational modes that change their intensity, we carried out DFT calculations on MMB at the RB3LYP-6311++G(d,p) theory level (Figure 3A). ${ }^{18}$ Results indicate that MMB belongs to $C_{1}$ point group of symmetry, implying that it is not planar. However, assuming the strong interaction silver-thiol, ${ }^{19}$ where the ring is placed quasi perpendicular to the surface, ${ }^{20}$ and considering that the surface electric field, $\vec{E}$, effectively has only a normal component (Z direction in Figure $3 \mathrm{~B}),{ }^{21}$ the intensity of a vibrational mode is proportional to the square of scalar product of the electric field and the dipole moment derivative of the mode. ${ }^{22}$ This scenario defines two freedom degrees for the phenil ring to change its orientation upon interaction with other substances: $\theta$, the tilt angle of the $z$ axis of the mercaptobenzene unit with the surface normal $(Z)$, and $\chi$ as the twist angle of the molecular plane around the $z$ axis (which is $0^{\circ}$ when $y$ is parallel to the surface).

The theoretical Raman MMB spectrum shows good correlation with the experimental, which allows a safe assignation of the modes. The SERS spectrum of MBB shows low intensity of the out-of-plane modes, related to the ring plane, at 756 and $997 \mathrm{~cm}^{-1}$ of $\mathrm{MBB}$, indicating a perpendicular orientation of the ring against the surface. The addition of $\mathrm{H}_{1}$ to MMB increases the intensity of this modes slightly but, importantly, this effect becomes remarkable when $\mathrm{MB}-\mathrm{H}_{1}$ interacts with c-MYC as a consequence of its massive size ( $57 \mathrm{kDa})$. In fact, the appearance of the these out-of-plane bands at the same level of the intensity ring breathing at $\left(1075 \mathrm{~cm}^{-1}\right)$ indicates a flatter reorientation of the ring as compared with the surface. Additionally, the $\mathrm{N}-\mathrm{C}$ stretching mode $\left(1022 \mathrm{~cm}^{-1}\right)$ slightly in MB-H1 and greatly upon conjugation with c-MYC. Notably, for sensing applications it should be considered that in a given situation where the amount $\mathrm{MB}-\mathrm{H}_{1}$ is larger than that of c-MYC, someMB-H1 molecules will interact with cMYC while other will remain unaffected. Thus for protein quantificationthe ratiometric peak intensities $\mathrm{I}_{756} / \mathrm{I}_{1075}$ (ratio between the out-of-plane $\mathrm{CCH}$ deformation at $756 \mathrm{~cm}^{-1}$ and the in-plane ring breathing at $1075 \mathrm{~cm}^{-1}$ ).

The efficiency of our sensor was demonstrated with both tumor cell lines and real human samples, while ELISA was performed to validate the results. The study has received ethical approval by the Ethics and Clinical Research Committee of the HM Hospitales Group, and all participants signed a written informed consent form. Figure $4 \mathrm{~A}$ shows a scheme of the protocol followed for the quantification of c-MYC by ELISA and SERS. Blood samples were obtained from two healthy donors and a patient diagnosed of ovarian adenocarcinoma (stage IV). The patient was in progression at the time of sample collection. The presence of the tumor was confirmed histologically in compliance with common standards. Each sample of peripheral blood $(8 \mathrm{~mL})$ was processed in the following $24 \mathrm{~h}$ after extraction to obtain the mononuclear cells by a Ficoll process. The mononuclear cells collected from the blood samples as well as those from an epithelial tumor cell line $\left(\mathrm{MCF}_{7}\right)$ were lysed and centrifuged. Supernatants were then extracted and, for ELISA, the total protein amount was quantified by the Bradford protein assay. Levels of c-MYC were then determined with a total-human c-MYC ELISA kit. In the case of SERS, SiO $@ A g @ M B-H 1$ (240 beads functionalized with $100 \mathrm{pM} \mathrm{MB-H1,} \mathrm{which} \mathrm{is} \mathrm{equivalent} \mathrm{to} \mathrm{a}$ concentration of $2.5 \times 105$ molecules per bead) were directly added to each of the supernatants up to a final concentration of 200 beads $/ \mathrm{mL}$. Then, $100 \mu \mathrm{L}$ aliquots were cast on glass slides, and beads were analyzed by SERS before the evaporation of the solvent. Figure $4 \mathrm{~B}$ shows the SERS spectra for both c-MYC standards (in dotted thin lines), the same as used for calibration in ELISA, and the real human samples (in solid thick lines). The corresponding calibrations curves obtained for each method are presented in Figure ${ }_{4} \mathrm{C}$. Notably, both ELISA and SERS show adequate correlation coefficients with analogous c-MYC detection limits but a slightly larger standard deviation for the optical method. However, SERS results are obtained within minutes comparing to the 4-5 h preparations required for ELISA. Similar results are obtained for real samples (Figure $4 \mathrm{D}$ ). Finally, $\mathrm{MFC}_{7}$ yields to much higher values than real sample, probably because in that case all cells in the culture are cancerous, where in the real samples just a small fraction are tumor cells.

In summary, we developed a rapid, highly specific and sensitive SERS assay for the determination of c-MYC in real blood samples. The sensing scheme relies on the use of specifically designed hybrid materials consisting of silica micro- 

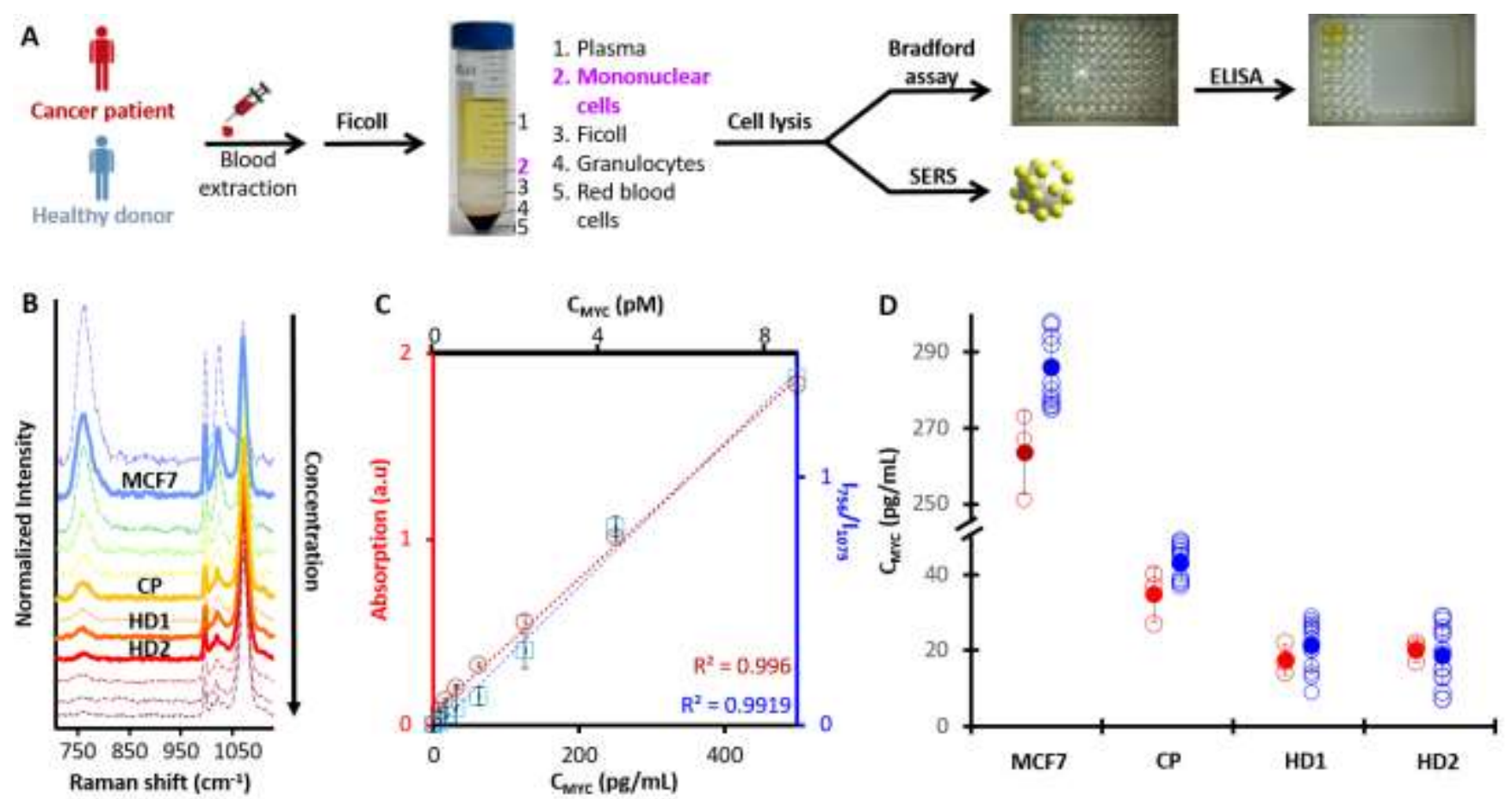

Figure 4. (A) Protocol for the isolation of mononuclear cells in human blood samples from a cancer patient and several healthy donors. (B) SERS spectra of $\mathrm{SiO}_{2} @ \mathrm{Ag} @ \mathrm{MB}-\mathrm{H}_{1}$ in the presence of decreasing concentrations of c-MYC (thin dotted lines) and of real samples (thick solid lines). (C) Calibration curves for ELISA (red) and our optical sensor (blue). (D) Results obtained for an epithelial tumor cell line (MCF7), and samples extracted from a cancer patient (CP) and two healthy donors (HD1 and HD2). ELISA in red, and optical sensor in blue. Concentration of c-MYC per million of cells.

particles rather homogenously coated with interacting silver nanoparticles. The metallic surfaces are bioderivatized with a c-MYC binding peptide modified with a 4-mercapto- $N$ methylbenzamide antenna (MB-H1) that transduces the specific c-MYC recognition events into a measurable alteration of the SERS signal from MB-H1. Deconvolution of the chemoreceptor vibrational fingerprint allowed us to identify characteristic vibrational modes affected by c-MYC complexation. The extent of such spectral changes was quantitatively correlated with the c-MYC content in complex biological media of real samples.

\section{ASSOCIATED CONTENT}

\section{Supporting Information}

Experimental section; general peptide synthesis procedures; synthesis, characterization and functionalization of $\mathrm{SiO}_{2} @ \mathrm{Ag}$ beads; cell and human samples preparation. Additional SEM/TEM and SERS spectra. This material is available free of charge via the Internet at http://pubs.acs.org.

\section{AUTHOR INFORMATION}

\section{Corresponding Authors}

E-mails: ramon.alvarez@urv.cat; joseluis.mascarenas@usc.es; egarcia@hmhospitales.com

\section{Notes}

The authors declare no competing financial interests.

\section{ACKNOWLEDGMENT}

This work was funded by Marie Curie Actions ( $\mathrm{FP}_{7} / 2007-$ 2013, TECNIOspring no. 600388 and PrioSERS FP72014623527), the European Research Council (Advanced Grant
No. 340055) the Spanish MINECO (CTQ2014-59808R, SAF2013-41943-R， CTQ2015-70698-R， CTQ2013-49317-EXP and the orfeo-cinqa network), the Generalitat of Catalonia (2014-SGR-480, AGAUR 2014052 and AGAUR 2014 054) the Xunta de Galicia (GRC2013-041), and Medcom Advance SA.

\section{REFERENCES}

(1) Buder, A.; Tomuta, C.; Filipits, M. Curr. Opin. Oncol. 2016, 28, 130.

(2) Ignatiadis, M.; Lee, M.; Jeffrey, S. S. Clin. Cancer Res. 2015, 21, 4786.

(3) Crowley, E.; Di Nicolantonio, F.; Loupakis, F.; Bardelli, A. Nat. Rev. Clin. Oncol. 2013, 10, 472.

(4) Dang, Chi V. Cell 2012, 149, 22

(5) Helm, F.; Kammertoens, T.; Lehmann, F. M.; Wilke, A.; Bruns, H.; Mautner, J.; Bornkamm, G. W.; Gerbitz, A. PLoS ONE 2013, 8, e77375.

(6) Nie, Z; Hu, G.; Wei, G.; Cui, K.; Yamane, A.; Resch, W.; Wang, R.; Green, Douglas R.; Tessarollo, L.; Casellas, R.; Zhao, K.; Levens, D. Cell 2012, 151, 68.

(7) Schlücker, S. Angew. Chem. Int. Ed. 2014, 53, 4756.

(8) Alvarez-Puebla, R. A.; Agarwal, A.; Manna, P.; Khanal, B. P.; Aldeanueva-Potel, P.; Carbó-Argibay, E.; Pazos-Pérez, N.; Vigderman, L.; Zubarev, E. R.; Kotov, N. A.; Liz-Marzán, L. M. Proc. Natl. Acad. Sci. USA 2011, 108, 8157.

(9) Habuchi, S.; Cotlet, M.; Gronheid, R.; Dirix, G.; Michiels, J.; Vanderleyden, J.; De Schryver, F. C.; Hofkens, J. J. Am Chem. Soc. 2003, 125, 8446.

132,429 .

(10) Singhal, K.; Kalkan, A. K. J. Am. Chem. Soc. 2010,

(11) aLin, L.; Tian, X.; Hong, S.; Dai, P.; You, Q.; Wang, R.; Feng, L.; Xie, C.; Tian, Z.-Q.; Chen, X. Angew. Chem. Int. Ed. 2013, 52, 7266; $\quad$ bFeng, M.; Tachikawa, H. J. Am. Chem. Soc. 2008, 130,7443 .

(12) Alvarez-Puebla, R. A.; Liz-Marzan, L. M. Chem. Soc. Rev. 2012, 41, 43. 
(13) Guerrini, L.; Arenal, R.; Mannini, B.; Chiti, F. Pini, R.; Matteini, P.; Alvarez-Puebla, R. A. ACS Appl. Mater. Interfaces 2015, 7, 9420 .

(14)

aGuerrini, L.; Pazos, E.; Penas, C.; Vázquez, M. E.; Mascareñas, J. L.; Alvarez-Puebla, R. A. J. Am. Chem. Soc. 2013, 135 10314; bLiu, S.; Zhang, X.; Luo, W.; Wang, Z.; Guo, X.; Steigerwald, M. L.; Fang, X. Angew. Chem. Int. Ed. 2011, 50, 2496; cWang, Y.; Lee, K.; Irudayaraj, J. Chem. Comm. 2010, 46, 613.

(15) aDraeger, L. J.; Mullen, G. P. J. Biol. Chem. 1994,

269,1785

2005, 4, 1076 . bBidwell, G. L.; Raucher, D. Mol. Cancer Ther.

(16) Decher, G. Science 1997, 277, 1232

(17) aMoskovits, M.; Suh, J. S. J. Phys. Chem. 1984, 88,

5526

Moskovits, M.; Suh, J. S. J. Phys. Chem. 1988, 92, 6327.

(18) Frisch, M. J.; Trucks, G. W.; Schlegel, H. B.;

Scuseria, G. E.; Robb, M. A.; Cheeseman, J. R.; Scalmani, G.; Barone, V.; Mennucci, B.; Petersson, G. A.; Nakatsuji, H.; Caricato, M.; Li, X.; Hratchian, H. P.; Izmaylov, A. F.; Bloino, J.; Zheng, G.; Sonnenberg, J. L.; Hada, M.; Ehara, M.; Toyota, K.; Fukuda, R.; Hasegawa, J.; Ishida, M.; Nakajima, T.; Honda, Y.; Kitao, O.; Nakai, H.; Vreven, T.;
Montgomery, J. A.; Peralta, J. E.; Ogliaro, F.; Bearpark, M.; Heyd, J. J.; Brothers, E.; Kudin, K. N.; Staroverov, V. N.; Kobayashi, R.; Normand, J.; Raghavachari, K.; Rendell, A.; Burant, J. C.; Iyengar, S. S.; Tomasi, J.; Cossi, M.; Rega, N.; Millam, J. M.; Klene, M.; Knox, J. E.; Cross, J. B.; Bakken, V.; Adamo, C.; Jaramillo, J.; Gomperts, R.; Stratmann, R. E.; Yazyev, O.; Austin, A. J.; Cammi, R.; Pomelli, C.; Ochterski, J. W.; Martin, R. L.; Morokuma, K.; Zakrzewski, V. G.; Voth, G. A.; Salvador, P.; Dannenberg, J. J.; Dapprich, S.; Daniels, A. D.; Farkas; Foresman, J. B.; Ortiz, J. V.; Cioslowski, J.; Fox, D. J. Wallingford CT, 2009.

(19) Sellers, H.; Ulman, A.; Shnidman, Y.; Eilers, J. E. Journal of the American Chemical Society 1993, 115, 9389.

(20) Chang, S.-C.; Chao, I.; Tao, Y.-T. Journal of the American Chemical Society 1994, 116, 6792.

(21) Ataka, K.-i.; Yotsuyanagi, T.; Osawa, M. J. Chem. Phys 1996, 100, 10664.

(22) Allara, D. L.; Nuzzo, R. G. Langmuir 1985, 1, 52.

(23) aStöhr, J.; Outka, D. A. Phys. Rev. B 1987, 36 ,

7891; $\quad$ bRoberts, J. T.; Friend, C. M. J. Chem. Phys 1988, 88, 7172.

\section{Table of Contents}

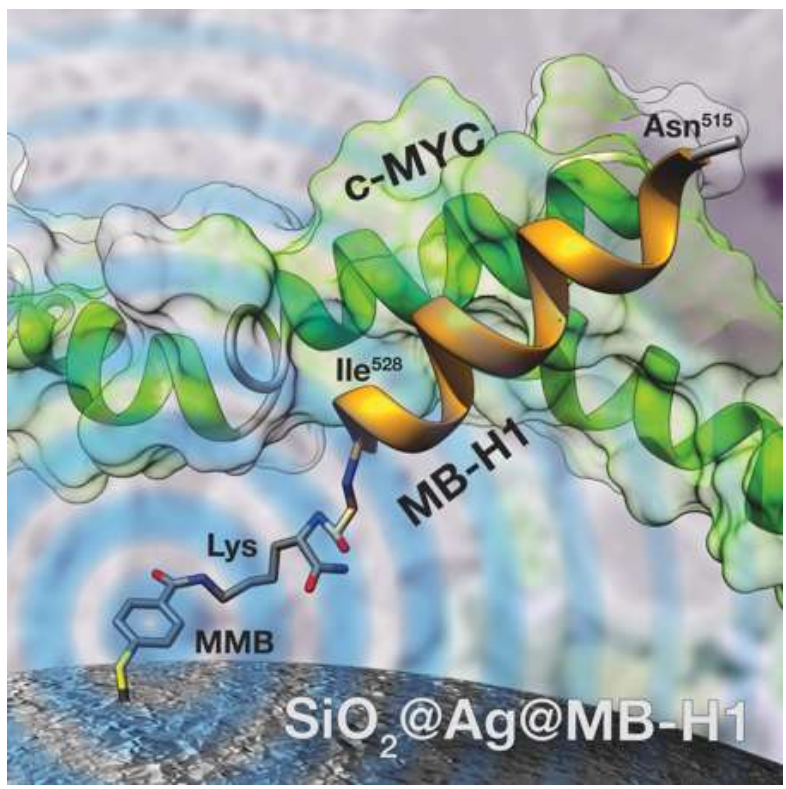

